\title{
Characteristics of the New Coronavirus Named SARS-CoV-2 Responsible for an Infection Called Coronavirus Disease 2019 (COVID-19)
}

\author{
Modou Mamoune Mbaye ${ }^{1^{*}}$, Bouchra El Khalfi $^{1}$, Said El Hafiane ${ }^{2}$ \\ and Abdelaziz Soukri ${ }^{1}$
}

${ }^{1}$ Physiopathology Molecular Genetics and Biotechnologies Laboratory, Faculty of Sciences Ain Chock, Center of Health and Biotechnology, Hassan II University, Casablanca, Morocco.

${ }^{2}$ Laboratory of Medical Analyzes, Orbio, Casablanca, Morocco.

Authors' contributions

This work was carried out in collaboration among all authors. All authors read and approved the final manuscript.

Article Information

DOI: $10.9734 / A R R B / 2020 / v 35 i 630237$ Editor(s):

(1) Asst. Prof. Sujan Banik, Noakhali Science and Technology University, Bangladesh. Reviewers:

(1) Joseph P. Myers, Northeast Ohio Medical University, USA (2) Benjamin Longo, Lomo University of Research, DR Congo and Walter Sisulu University, South Africa. (3) Sambashiva Daravath, Osmania University, India. Complete Peer review History: http://www.sdiarticle4.com/review-history/56977

Review Article

Received 25 April 2020

Accepted 19 May 2020

Published 08 July 2020

\section{ABSTRACT}

The new coronavirus called Covid-19, previously known as 2019-nCOV that has been reported in China, is rapidly spreading around the world at breakneck speed. Covid-19, a virus that was unknown to us before the outbreak in Wuhan (China) in December 2019, remains a major public health problem today. However, a new coronavirus named SARS-CoV-2 has been identified as responsible for this disease. Human-to-human transmission is no longer a matter of debate. In general, 2019-nCOV is an infectious, acute resolved disease, but it can also be very fatal especially with certain comorbidities such as hypertension, diabetes, coronary heart disease, cerebral infarction or even chronic bronchitis. The main symptoms of Covid-19 are fever, cough, shortness of breath, chest tightness / pain, respectively. Until now, the source of the virus and the pathogenesis of this disease remain unknown. Considering the speed of propagation, the mortality rate in the world and its economic consequences, it is urgent to find drugs for the treatment even a vaccine in order to cut short the Covid-19. In this article, we will try to detail all the information relating to this virus. 
Keywords: Covid-19; mortality; coronavirus; health; virus.

\section{INTRODUCTION}

Coronaviruses are a large family of viruses that can be pathogenic in humans and animals [1]. Detection in the city of Wuhan, a province of Hubei in China in December 2019, of a new virus designated SARS-CoV-2 responsible for a new infection called Coronavirus Disease 2019 (Covid-19) by the World Organization for health (WHO) [2]. Coronaviruses have long caused mild respiratory infections in humans, with clinical manifestations ranging from a common cold to more serious illnesses like severe acute respiratory syndrome (SARS) and Middle Eastern respiratory syndrome (MERS) [3]. Today, covid-19 poses a very serious threat to public health as the pandemic continues worldwide. Moreover, Covid-19 affects more than 193 countries, territories around the world, more than $3,955,984$ people are infected including 275,188 cured, and almost 1,319,306 have died [4]. In this sense, almost all of the countries affected have launched a level 1 public health intervention [5]. The purpose of this article in the literature is to provide a rapid review of the characteristics of the Covid-19 pandemic, including the pandemic, the pathogenic and clinical characteristics of the coronavirus, and the diagnosis of SARS-CoV-2 infection (Covid-19).

\section{PANDEMIC CORONAVIRUS DISEASE COVID-19}

SARS-CoV-2, the virus responsible for Covid-19 for (Coronavirus Disease 2019), responsible for an epidemic whose epicenter was in China [6]. Although the majority of active cases and deaths were in mainland China, today's pandemic environment is evolving in a pandemic context due to the surge in active cases (Fig. 1), deaths worldwide (Fig. 2) and the distribution of cases worldwide (Fig. 3) [7]. According to Worldometer COVID-19 data from April 29, 2020, of the 212 countries and territories that still withstand the worst of Covid-19, the United States remains the most affected, with nearly 1,322,223 confirmed cases and more than 78,622 deaths [8]. However, the European continent has claimed the most victims, with more than 152,173 deaths [8]. Italy has recorded 219,070 confirmed cases and 30,560 deaths [8]. Like Italy, Spain recorded 264,663 confirmed cases and 26,621 deaths [8]. While the United Kingdom has registered 219,183 confirmed cases and 31,855 deaths [8]. To date, there have been a total of $4,201,014$ confirmed cases and 284,152 deaths worldwide [8].

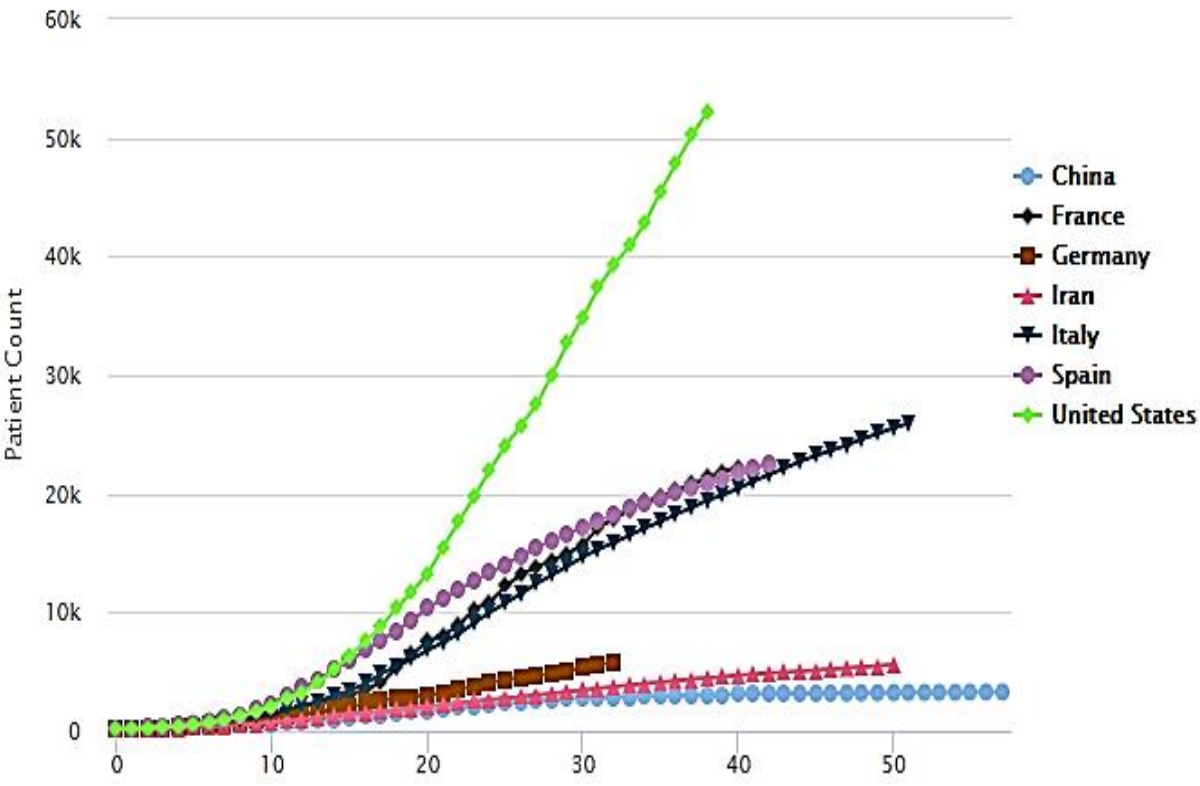

Fig. 1. Cumulative number of deaths according to Worldometer COVID-19 data from 04/27/2020 


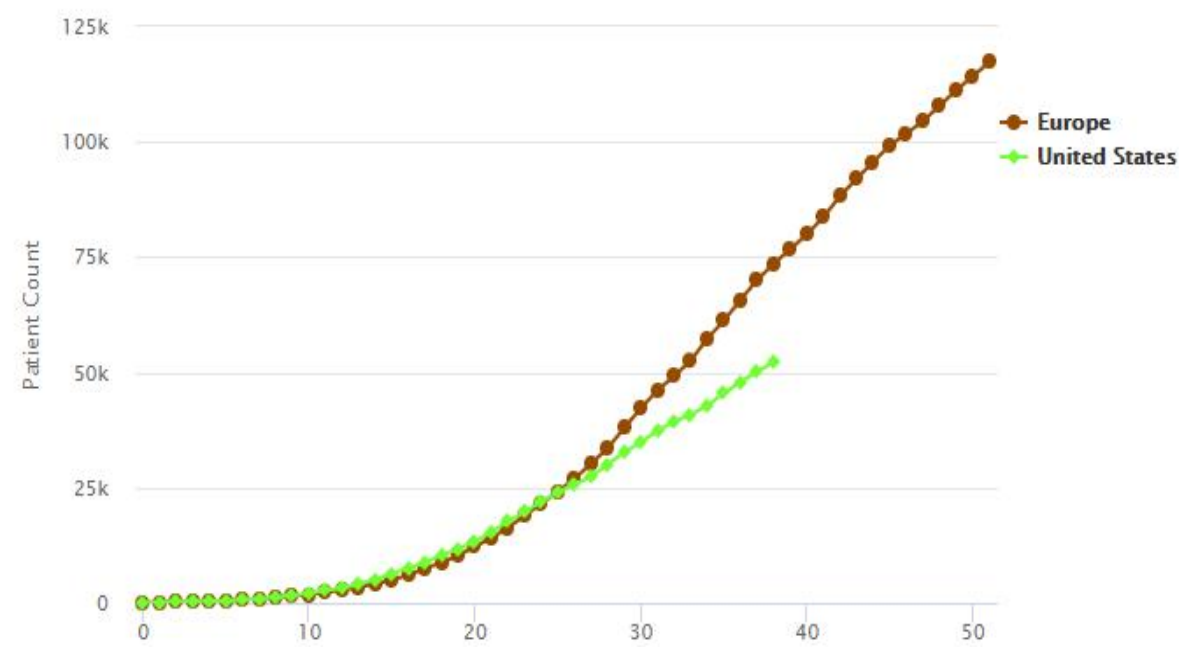

Fig. 2. Cumulative number of deaths Europe vs. USA according to Worldometer COVID-19 data from 04-27-2020

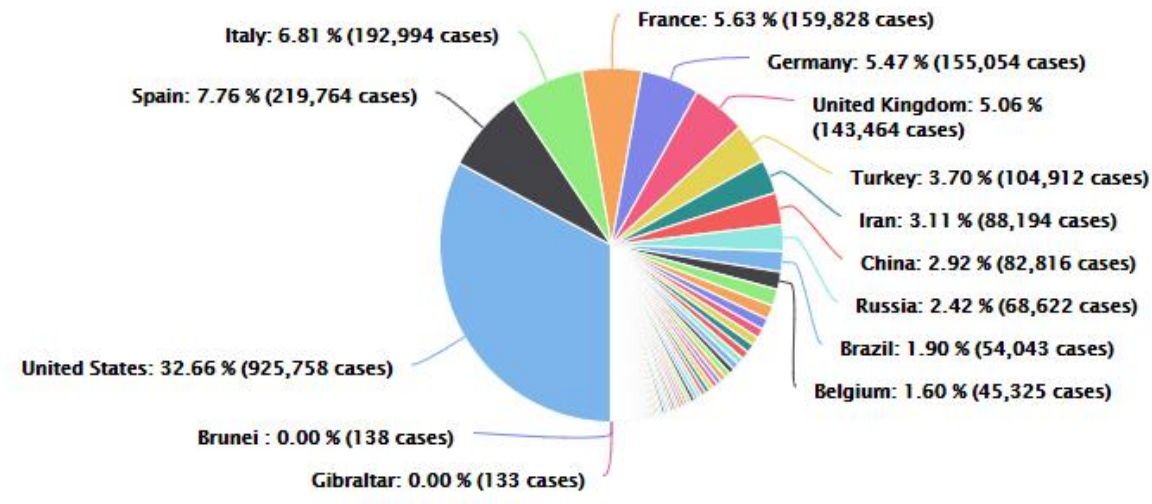

Fig. 3. Countries cases distribution according to Worldometer COVID-19 data from 04-27-2020

\section{PATHOGENIC CHARACTERISTICS OF CORONAVIRUS DISEASE 2019 (COVID-19)}

Coronavirus is a single-stranded positive RNA (+ ssRNA) virus, belonging to the order Nidovirales, family Coronaviridae and subfamily Orthocoronavirinae (Fig. 4) [9]. Based on serotype and genome characteristics, the subfamily of coronaviruses is divided into four genera: $\alpha \beta \gamma$ and $\delta$ [10]. According to ShengQun Deng et al, there are six known coronavirus types that can infect humans, namely: 229E, NL63 of the genus $\alpha$, OC43, HKU1, Middle East Respiratory Syndrome Associated Coronavirus
(MERSr-CoV) and Severe Acute Respiratory Syndrome Associated Coronavirus (SARSr-CoV) of the genus $\beta$ [11]. In addition, according to the team of Sheng-Qun Deng et al. the coronavirus that was isolated from the lower respiratory tract of patients with unidentified pneumonia in the city of Wuhan, a Hubei province in China in December 2019 is the seventh coronavirus that can infect humans [12]. According to the World Health Organization report, coronaviruses are sensitive to heat and can be killed at $50^{\circ} \mathrm{C}$ for 30 minutes [13]. In addition, ether, $75 \%$ ethanol [14], chlorine disinfectant [15], peracetic acid and chloroform can effectively inactivate the virus [16], but not Chlorhexidine [17]. 


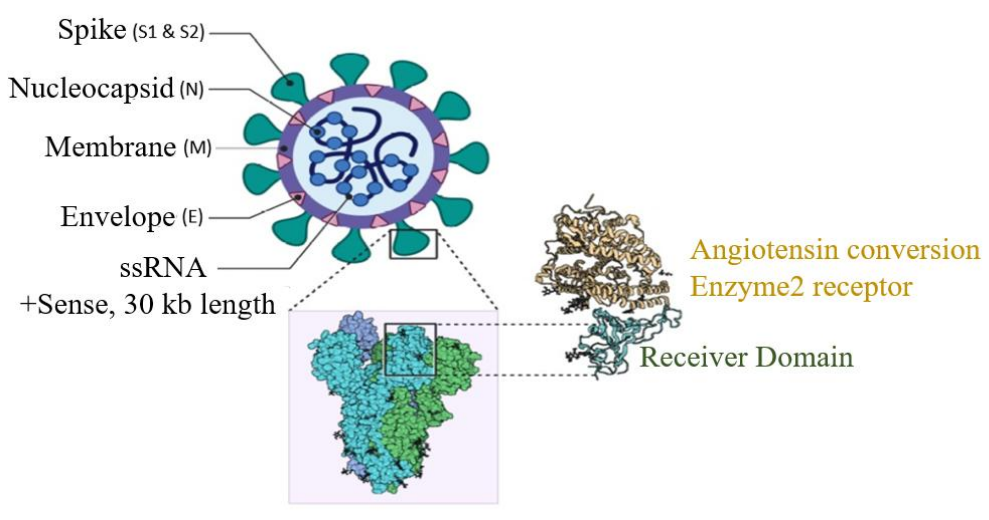

Fig. 4. Structure of SARS-CoV-2

\section{CHARACTERISTICS OF CORONA- VIRUS DISEASE 2019 (COVID-19)}

\subsection{Pathological Features of Coronavirus Disease 2019 (Covid-19)}

The pathological features of Covid-19 are fever [18], signs of respiratory difficulties such as cough or shortness of breath [19], fever above $37.5^{\circ} \mathrm{C}$ [20], dry or wet cough [21], respiratory signs such as [22], cough [23], tightness and/or chest pain [24], sometimes with dyspnoea (shortness of breath) [25], chills [26], aches and pains [27], unusual fatigue [28], and headaches [29]. The team of Zhe Xu et al. stated that in severe cases, we could witness a very rapid transformation of pathological characteristics into acute respiratory distress syndrome, septic shock, metabolic acidosis that is difficult to correct and coagulation dysfunction [30]. In fact, Chen $\mathrm{N}$ et al.'s team reported symptoms in percentages of 99 confirmed cases. Common symptoms were fever (83\%), cough (82\%), bilateral pneumonia $(75 \%)$, shortness of breath $(31 \%)$, muscle pain $(11 \%)$, confusion $(9 \%)$, headache $(8 \%)$, sore throat $(5 \%)$, rhinorrhea $(4 \%)$, chest pain $(2 \%)$, diarrhea $(2 \%)$ and vomiting and/or nausea (1\%) [31]. In the same vein of research, the team of Sheng-Qun Deng et al. have stated that some patients develop mild onset symptoms, no fever and generally recovered after one week [11]. According to the Senegalese Ministry of Health and Social Action, a few patients who tested positive for Covid-19 showed no pathological features [32]. The team of Liu $Y$ et al, states that almost all patients have a favourable prognosis, although some patients remain in critical condition or do not survive [33]. Cases in children are relatively mild [34].

\subsection{COVID-19 Incubation Time}

A study conducted by Annals of Internal Medicine analyzed data from 181 patient records, $60 \%$ of which were men who tested positive for Covid-19 and had an average age of 44.5 years [35]. These people were infected after visiting Wuhan, the site of the emerging epidemic, or after having been in contact with an infected person between 4 January and 24 February 2020 [36]. The results validate the current quarantine recommendations as most patients who become symptomatic do so within 11 or 12 days and the vast majority within 14 days.

\section{RISK FACTORS FOR COVID-19}

According to researchers affiliated with the China Center for Disease Control, the presence of a chronic disease can increase the risk of complications [37]. It is in a sense that the team of Huipeng et al. reported the percentage composition of symptoms in 41 people who tested positive for covid-19 and died thereafter [38]. The percentages were respectively (20\%) for diabetes [38], (15\%) for hypertension [39] and $(15 \%)$ for cardiovascular disease [40]. In addition, the cases of death in Morocco are a perfect illustration since most of the deaths were elderly people [41]. Same, for Senegal where 15 of the 17 dead were elderly people suffering from chronic diseases. While, the other two were patients who were 37 years old but suffered from chronic diseases such as asthma, diabetes [42]. Besides, the death of the vice-president of Burkina Faso who was diabetic is also a perfect one illustration [43]. In other words, the majority of people who died from covid-19 were elderly 
people with high blood pressure, diabetes, coronary artery disease, asthma, or having a compromised immune system etc. [44]. Therefore, comorbidities in patients with coronavirus 2019 (Covid-19) are probably important factors leading in most cases to death [45].

\section{DIAGNOSIS OF CORONAVIRUS DISEASE 2019 INFECTION (COVID-19)}

The diagnosis of coronavirus 2019 (COVID-19) is a public health problem because COVID-19 is rapidly spreading around the world, whereas current diagnostic methods for identifying the virus have limits [46]. However, the standard diagnostic method used is the real-time polymerase chain reaction (RT-PCR) to detect viral nucleotides from samples obtained by oropharyngeal or nasopharyngeal swab, or by bronchoalveolar lavage or tracheal aspiration [47]. Recent reports have revealed that RT-PCR has such a low sensitivity of around 60 to $71 \%$ for the detection of COVID-19 [47,48,49]. According to Fang et al, this low sensitivity is due to a low viral load present in the samples or to a laboratory error [48]. According to the team of Kanne et al. the other problem of RT-PCR is the appearance of false negatives up to $25 \%$ not only hampering the efforts of quarantine because it requires repeated tests but increases the need for test kits and infrastructure [49].

The team of Harrison et al. showed that chest CT had a sensitivity of about 56 to $98 \%$ in the detection of COVID-19 in the early stages of the onset of the disease. Thus, thoracic CT can be useful to correct false negatives that can be obtained by RT-PCR during the early stages of disease development [50]. In fact, radiologists in China and the United States have distinguished COVID-19 from viral pneumonia on chest CT with high specificity but moderate sensitivity [50]. Despite its great sensitivity in the diagnosis of COVID-19, the thoracic CT appearances of COVID 19 pneumonia are not specific [50].

According to the National Health Commission of the People's Republic of China and the National Administration of Traditional Chinese Medicine: Suspect cases were all individuals who had a history of travel or residence in the district(s) with case report, in contact with patients positive with nucleic acid detection, in contact with patients with fever and respiratory symptoms in the district or are the confirmed positive patients [51]. While, confirmed cases were suspect cases with one of the following etiological evidence: individuals who were identified positive with SARS-CoV-2 RNA by real-time fluorescent RT$\mathrm{PCR}$ of respiratory or blood samples for the detection of novel coronavirus nucleic acids [52] and individuals whose viral gene sequencing in respiratory or blood samples was highly homologous to known novel coronaviruses [53].

\section{CLINICAL TYPING OF CONFIRMED CASES}

According to researchers affiliated with the Chinese Centre for Disease Control, the clinical typing of confirmed cases had occurred in several cases, namely: mild cases, i.e. people with mild symptoms and no evidence of pneumonia in the chest image [54]. common cases, i.e. persons with fever, respiratory symptoms and pneumonia on the chest image [55], severe cases, persons with dyspnea, respiratory rate $\geq 30$ times / $\mathrm{min}$; at rest, oxygen saturation of the fingers $\leq 93 \% ; \mathrm{PaO} 2 / \mathrm{FiO} 2 \leq$ $300 \mathrm{mmHg}(1 \mathrm{mmHg}=0.133 \mathrm{kPa}, \mathrm{PaO} 2$ : partial blood pressure of oxygen, FiO2: fractional concentration of inhaled oxygen) [56] and finally critical cases, i.e. people who in addition to the above-mentioned elements have respiratory insufficiency [57]. These cases require mechanical ventilation [58], monitoring and treatment in an intensive care unit (ICU) due to the presence of other organ failures and hospitalization [59].

\section{A "PROMISING" DRUG AGAINST CORONAVIRUS DISEASE 2019 INFECTION (COVID-19)}

Coronavirus 2019 (Covid-19) is spreading at an alarming rate. Given its pathogenesis and its lethality, scientists are working to discover drugs for its effective treatment. Therefore, there is the rush for drugs like hydroxychloroquine [60], azithromycin [61], steroids [62], inflammatory response inhibitors like tocilizumab [63] and antivirals like remdesevir [64]. Chloroquine, the most widely used antimalarial drug for many decades, has demonstrated apparent efficacy and acceptable safety against respiratory disease caused by the new coronavirus (SARSCoV-2) in multicentre clinical trials in China [64]. The results of the study by Gao $\mathrm{J}$ et al. in more than 100 patients showed the superiority of chloroquine over the control group in terms of reduction of the exacerbation of pneumonia, the duration of the symptoms and the viral clearance 
delayed, all in the absence of severe side effects [65]. This led to the inclusion of chloroquine in the recommendations for the prevention and treatment of pneumonia with Covid-19 in China [66]. In the same vein of research, the team of Grein and al. through a 10-day course of remdesivir for compassionate use consisting of administering $200 \mathrm{mg}$ intravenously on day 1, followed by $100 \mathrm{mg}$ per day for 9 days out of a cohort of 61 patients who had a confirmed SARS-CoV-2 infection and an oxygen saturation of $94 \%$ showed that 53 of the patients or $68 \%$ had clinical improvement [67]. In this same research into therapeutic strategy, the team of $\mathrm{Xu}$ and al, showed that tocilizumab effectively improves clinical symptoms and suppresses the deterioration of severe COVID-19 patients [68]. Thus they saw that patients diagnosed with severe or critical COVID-19 who received tocilizumab in addition to routine therapy between February 5 and 14, 2020 saw their fevers return to normal the first day, a reduction in their oxygen supply, the percentage of lymphocytes in the peripheral blood had returned to normal, a decrease in the C-reactive protein and that no obvious adverse effects were observed [69]. Apart from all that, it should be noted that currently, according to the $\mathrm{WHO}$ and the Centers for Disease Control and Prevention (CDC) in the United States, no specific drug is recommended to prevent or treat the new coronavirus because none of the treatments $n$ 'has yet been documented to be effective as in WHO and CDC statements [70].

\section{DISCUSSION}

The recent outbreak of unknown severe pneumonia in China is caused by a new coronavirus named 2019-nCoV [71], which was subsequently designated as SARS-CoV-2 by the International Committee on Virus Taxonomy. This virus and SARSr-CoV / MERSr-CoV share a common ancestor [72]. The team of Guo et al, through a comparison of SARS-CoV-2and MERSr-CoV showed that SARS-CoV-2leads to much lower mortality in patients with both infections, but both have comparable infection capacities [73]. A review of fatal cases in the literature indicates that co-morbidities such as hypertension, diabetes, coronary heart disease, cerebral infarction and chronic bronchitis have been shown to be dangerous factors leading to death [74]. The virus can be transmitted from person to person [75]. The most effective prevention and control measures include identifying suspect patients and close contacts, confirming patients and virus carriers, and blocking transmission through isolation, disinfection and personal protection [76]. Therefore, early detection, isolation and treatment of patients are key measures to control the source of infection and reduce the rate of infection [77]. It is also crucial to avoid nosocomial infections by strengthening the management of medical staff and patients [52]. Health education with knowledge for disease prevention and control is also important.

The diagnosis of coronavirus 2019 (COVID-19) is a headache given the wide range of current diagnostic methods to identify the virus and the limitations of all these methods [46]. Even if, the standard diagnostic method used is the real-time polymerase chain reaction (RT-PCR), it has a number of weaknesses, namely: a low sensitivity of around 60 to $71 \%$ for the detection of COVID 19 , the appearance of false negatives up to $25 \%$. These limits not only hamper quarantine efforts, but also require repeated testing and an increased need for test kits and infrastructure [49].

On the other hand, chest CT despite a sensitivity of around 56 to $98 \%$ in the detection of COVID19 can be useful to correct false negatives that can be obtained by RT-PCR [50]. In fact, radiologists in China and the United States have succeeded in distinguishing COVID-19 from viral pneumonia on chest CT with high specificity and moderate sensitivity [50]. However, it must be recognized that despite the sensitivity in the diagnosis of COVID-19, the thoracic CT appearances of COVID 19 pneumonia are not specific [50].

Currently, the World Health Organization and the Centers for Disease Control and Prevention in the United States claim that there is no specific medication recommended to prevent or treat the new coronavirus (2019-nCoV). Therefore, there is the rush for antiviral drugs like remdesevir [64], hydroxychloroquine [60], azithromycin [61], steroids and inflammatory response inhibitors (tocilizumab) [63].

The discovery in China of the in vitro activity of chloroquine against SARS-CoV-2 in culture tests on Vero E6 cells with effective concentrations of $50 \%$ and $90 \%$ (EC50 and EC90 values) of 1.13 $\mu \mathrm{M}$ and $6.90 \mu \mathrm{M}$, respectively (antiviral activity being observed when adding this drug before or after a viral infection of the cells has generated great enthusiasm worldwide) [49]. Because the 
administration of $500 \mathrm{mg}$ chloroquine twice daily in patients with mild, moderate and severe forms of Covid-19 pneumonia could reduce the length of hospital stay and improve the progression of pneumonia caused by the new coronavirus (SARS-CoV-2) [52], 500 mg chloroquine twice daily is recommended in patients with mild, moderate and severe forms of Covid-19 pneumonia. The authorisation of chloroquine in the treatment of Covid-19 is a perfect illustration of this [42].

\section{CONCLUSION}

The covid-19 pandemic remains a real public health problem given the number of countries affected and deaths worldwide. The prevalence of co-morbidities in COVID-19 patients with hypertension, diseases of the respiratory system, cardiovascular disease and advanced age may be risk factors for severe versus non-severe patients. The use of chloroquine can be supported by expert opinion, the clinical use of this drug in patients with COVID-19 must respect the MEURI framework or after ethical approval as a test, as indicated by WHO. There is an urgent need for high quality coordinated clinical trial data from different parts of the world.

\section{COMPETING INTERESTS}

Authors have declared that no competing interests exist.

\section{REFERENCES}

1. Fehr AR, Anthony R, Perlman, Stanley. Coronaviruses: An overview of their replication and pathogenesis. In: Coronaviruses. Humana Press, New York, NY. 2015;1:23.

2. World Health Organization et al. Coronavirus disease 2019 (COVID-19): Situation Report. 2020;51.

3. Chan Jasper FW, Lau Susanna KP, Kelvin $\mathrm{KW}$, et al. Middle East respiratory syndrome coronavirus: Another zoonotic betacoronavirus causing SARS-like disease. Clinical Microbiology Reviews. 2015;28:265-522.

4. Sohrabi C, Alsafi Z, O'Neill N, Khan M, Kerwan A, Al-Jabir A, Agha R. World Health Organization declares global emergency: A review of the 2019 novel coronavirus (COVID-19). International Journal of Surgery; 2020.
5. Remuzzi, Andrea, Giuseppe. COVID-19 and Italy: What next? The Lancet; 2020.

6. Gentile I, Abenavoli L. COVID-19: Perspectives on the potential novel global threat. Reviews on Recent Clinical Trials. 2020;15:2-2020.

7. Li JY, You Z, Wang Q, Zhou ZJ, Qiu Y, Luo $R$, Ge $X Y$. The epidemic of 2019novel-coronavirus (2019-nCoV) pneumonia and insights for emerging infectious diseases in the future. Microbes and Infection. 2020;22:280-85.

8. www.worldometers.info Worldometer; 2020.

(27-04-2020)

9. Deng SD, Peng HJ. Characteristics of and public health responses to the coronavirus disease 2019 outbreak in China. Journal of Clinical Medicine. 2020;9:575.

10. Wu Z, McGoogan JM. Characteristics of and important lessons from the coronavirus disease 2019 (COVID-19) outbreak in China: Summary of a report of 72314 cases from the Chinese Center for Disease Control and Prevention. JAMA; 2020.

11. Xu Z, Shi L, Wang Y, Zhang J, Huang L, Zhang, Tai $Y$. Pathological findings of COVID-19 associated with acute respiratory distress syndrome. The Lancet Respiratory Medicine; 2020.

12. Chen H, Guo J, Wang C, Luo F, Yu X, Zhang W, Liao J. Clinical characteristics and intrauterine vertical transmission potential of COVID-19 infection in nine pregnant women: A retrospective review of medical records. The Lancet. 2020;10226: 809-815.

13. Han $Y$, Zeng $H$, Jiang $H$, Yang $Y$, Yuan $Z$, Cheng $X$, Zhu J. CSC expert consensus on principles of clinical management of patients with severe emergent cardiovascular diseases during the COVID-19 epidemic. Circulation; 2020.

14. World Health Organization. Considérations relative's au placement en quarantaine de personnes dans le cadre de l'endiguement de la maladie à coronavirus 2019 (COVID19): Orientations provisoires, 29 février 2020. Organisationmondiale de la Santé; 2020.

15. Ding Jinli, Liu Yaou, Fu Haihong, et al. Experience on radiological examinations and infection prevention for COVID-19 in radiology department. Radiology of Infectious Diseases; 2020. 
16. Chen $\mathrm{H}$, Guo J, Wang $\mathrm{C}$, Luo F, $\mathrm{Yu} X$, Zhang W, Liao J. Clinical characteristics and intrauterine vertical transmission potential of COVID-19 infection in nine pregnant women: A retrospective review of medical records. The Lancet. 2020;395: 809-815.

17. Zheng YE, Zhang Yun, Wang Yi, et al. Chest CT manifestations of new coronavirus disease 2019 (COVID-19): A pictorial review. European Radiology. 2020;1:9.

18. Filatov Asia, Sharma Pamraj, Hindi Fawzi, et al. Neurological complications of coronavirus disease (covid-19): Encephalopathy. Cureus. 2020;12:3-7352.

19. Rzpici Alessandro, Maselli Roberta, Colombo Matteo, et al. Coronavirus (COVID-19) outbreak: What the department of endoscopy should know. Gastrointestinal Endoscopy; 2020.

20. Chan KamWa, Wong Vivian Taam, Tang Sydney Chi Wai. COVID-19: An update on the epidemiological, clinical, preventive and therapeutic evidence and guidelines of integrative Chinese-Western Medicine for the Management of 2019 Novel Coronavirus Disease. The American Journal of Chinese Medicine. 2020;1-26.

21. Wu Jian, Liu Jun, Zhao Xinguo, et al. Clinical characteristics of imported cases of COVID-19 in Jiangsu Province: A multicenter descriptive study. Clinical Infectious Diseases: An Official Publication of the Infectious Diseases Society of America; 2020.

22. Ysellier Migeon PA, Barasinski C, Gaucher L. cris Femmes par rapport au" risque Covid-19. Population. 2019;1:3.

23. Zheng Ying-Ying MA, Yi-Tong Zhang, JinYing, et al. COVID-19 and the cardiovascular system. Nature Reviews Cardiology. 2020;1-2.

24. Sohrabi Catrin, Alsafil Zaid, O'Neill Niamh, et al. World Health Organization declares global emergency: A review of the 2019 novel coronavirus (COVID-19). International Journal of Surgery; 2020.

25. Xu Zhe, SHI Lei, Wang Yijin, et al. Pathological findings of COVID-19 associated with acute respiratory distress syndrome. The Lancet Respiratory Medicine. 2020;8:420-422.

26. Lim Jaegyun, Jeon Seunghyun, Shin Hyun-Young, et al. Case of the index patient who caused tertiary transmission of COVID-19 infection in Korea: The application of lopinavir/ritonavir for the treatment of COVID-19 infected pneumonia monitored by quantitative RTPCR. Journal of Korean Medical Science. 2020;35:6.

27. Hu Zhiliang, Song $\mathrm{Ci}, \mathrm{Xu}$ Chuanjun, et al. Clinical characteristics of 24 asymptomatic infections with COVID-19 screened among close contacts in Nanjing, China. Science China Life Sciences. 2020;1:6.

28. World Health Organization. COVID-19 WHO African Region: External Situation Report 01; 2020.

29. Liu Y, Gayle AA, Wilder-Smith A, Rocklöv J. The reproductive number of COVID-19 is higher compared to SARS coronavirus. Journal of Travel Medicine; 2020.

30. Lauer SA, Grantz KH, Bi Q, Jones FK, Zheng, HR, Meredith Q, Lessler J. The incubation period of coronavirus disease 2019 (COVID-19) from publicly reported confirmed cases: Estimation and application. Annals of Internal Médicine; 2020.

31. Xu XW, Wu XX, Jiang XG, Xu KJ, Ying LJ, Ma C, Sheng JF. Clinical findings in a group of patients infected with the 2019 novel coronavirus (SARS-Cov-2) outside of Wuhan, China: Retrospective case series. BMJ. 2020;368.

32. Zhou F, Yu T, Du R, Fan G, Liu Y, Liu Z, Guan L. Clinical course and risk factors for mortality of adult inpatients with COVID-19 in Wuhan, China: A retrospective cohort study. The Lancet; 2020.

33. Rothan O, Hussin A, Byareddy, Siddappa $\mathrm{N}$. The epidemiology and pathogenesis of coronavirus disease (COVID-19) outbreak. Journal of Autoimmunity. 2020;10:24-33.

34. Bernheim $A$, Mei $X$, Huang $M$, Yang $Y$, Fayad ZA, Zhang N, Li S. Chest CT findings in coronavirus disease-19 (COVID-19): Relationship to duration of infection. Radiology. 2020;463:2020.

35. Daga MK, Kumar N, Aarthi J, Mawari G, Garg S, Rohatgi I. From SARS-CoV to Coronavirus Disease 2019 (COVID-19)-A brief review. Journal of Advanced Research in Medicine (E-ISSN: 2349-7181 \& P-ISSN: 2394-7047). 2019;6:41-9.

36. Ai T, Yang Z, Hou H, Zhan C, Chen C, Lv W, Xia L. Correlation of chest CT and RTPCR testing in coronavirus disease 2019 (COVID-19) in China: A report of 1014 cases. Radiology. 2020;200642.

37. National Health Commission of the People's Republic of China. The Latest 
Situation of Pneumonia Caused by Novel Corona Virus.

Available:http://www.nhc.gov.cn/xcs/yqtb/li st_gzbd.shtml

(Accessed on 19 February 2020)

38. Huipeng GE, Wang Xiufen, Yuan Xiangning, et al. The epidemiology and clinical information about COVID-19. European Journal of Clinical Microbiology \& Infectious Diseases. 2020;1.

39. Are patients with hypertension and diabetes mellitus at increased risk for COVID-19 infection? The Lancet. Respiratory Medicine; 2020.

40. Clerkin Kevin J, Fried Justin A, Raikhelkar Jayant, et al. Coronavirus disease 2019 (COVID-19) and cardiovascular disease. Circulation; 2020.

41. Ait Addi, Benksim R, Amine $A$, et al. COVID-19 outbreak and perspective in Morocco. Electron J Gen Med. 2020;17:4204.

42. Yang $\mathrm{Y}$, Peng $\mathrm{F}$, Wang $\mathrm{R}$, Guan $\mathrm{K}$, Jiang T, Xu G, Chang C. The deadly coronaviruses: The 2003 SARS pandemic and the 2020 novel coronavirus epidemic in China. Journal of Autoimmunity. 2020;10:24-34.

43. World Health Organization et al. Coronavirus disease 2019 (COVID-19): Situation Report. 2020;74.

44. Wu J, Liu J, Zhao X, Liu C, Wang W, Wang, Cao $H$. Clinical characteristics of imported cases of COVID-19 in Jiangsu province: A multicenter descriptive study. Clinical Infectious Diseases; 2020.

45. Wang $M$, Cao R, Zhang L, Yang X, Liu J, Xu M, Xiao G. Remdesivir and chloroquine effectively inhibit the recently emerged novel coronavirus (2019-nCoV) in vitro. Cell Research. 2020;30:269271.

46. Gao J, Tian Z, Yang X. Breakthrough: Chloroquine phosphate has shown apparent efficacy in treatment of COVID19 associated pneumonia in clinical studies. Bioscience Trends; 2020.

47. Ai Tao, et al. Correlation of chest CT and RT-PCR testing in coronavirus disease 2019 (COVID-19) in China: A report of 1014 cases. Radiology. 2020;200642.

48. Centers for Disease Control and Prevention. Interim Guidelines for Collecting, Handling and Testing Clinical Specimens from Persons under Investigation (PUIs) for Coronavirus Disease 2019 (COVID-19); 2020.
49. Fang $\mathrm{Y}$, Zhang $\mathrm{H}$, Xie J, Lin $\mathrm{M}$, Ying $\mathrm{L}$, Pang $P$, Ji W. Sensitivity of chest CT for COVID-19: Comparison to RT-PCR. Radiology. 2020;200432.

50. Kanne JP, Little BP, Chung JH, Elicker BM, Ketai LH. Essentials for radiologists on COVID-19: An update-radiology scientific expert panel; 2020.

51. Bai HX, Hsieh B, Xiong Z, Halsey K, Choi JW, Tran TML, Jiang XL. Performance of radiologists in differentiating COVID-19 from viral pneumonia on chest CT. Radiology. 2020;200823.

52. Colson P, Rolain JM, Lagier JC, Brouqui P, Raoult D. Chloroquine and hydroxychloroquine as available weapons to fight COVID-19. Int J Antimicrob Agents. 2020;10:59-32.

53. Pan Yang, Zhang Daitao, Yang Peng, et al. Viral load of SARS-CoV-2 in clinical samples. The Lancet Infectious Diseases. 2020;20:411-412.

54. Hui DS, Azhar I, Madani TA, Ntoumi F, Kock R, Dar O, Zumla A. The continuing 2019-nCoV epidemic threat of novel coronaviruses to global health-the latest 2019 novel coronavirus outbreak in Wuhan, China. International Journal of Infectious Diseases. 2020;91:264-266.

55. Lai Chih-Cheng, Liu Yen Hung, Wang Cheng-Yi, et al. Asymptomatic carrier state, acute respiratory disease, and pneumonia due to severe acute respiratory syndrome coronavirus 2 (SARSCoV-2): Facts and myths. Journal of Microbiology, Immunology and Infection; 2020.

56. Shanker Arun, Bhanu Divya, Alluri Anajani. Analysis of whole genome sequences and homology modelling of a $3 \mathrm{C}$ like peptidase and a non-structural protein of the novel coronavirus COVID-19 shows protein ligand interaction with an-Aza-peptide and a noncovalent lead inhibitor with possible antiviral properties; 2020.

57. Wang Shuo, Zha Yunfei, LI Weimin, et al. A fully automatic deep learning system for COVID-19 diagnostic and prognostic analysis. medRxiv; 2020.

58. World Health Organization. Coronavirus disease 2019 (COVID-19): Situation Report. 2020;51:51.

59. Cascella M, Rajnik M, Cuomo A, Dulebohn SC, Di Napoli R. Features, evaluation and treatment coronavirus (COVID-19). StatPearls Publishing; 2020.

60. Ferner RE, Aronson JK. Chloroquine and hydroxychloroquine in COVID-19; 2020. 
61. Gautret P, Lagier JC, Parola P, Meddeb L, Mailhe $M$, Doudier $B$, Honoré $S$. Hydroxychloroquine and azithromycin as a treatment of COVID-19: Results of an open-label non-randomized clinical trial. International Journal of Antimicrobial Agents. 2020;105949.

62. Russell B, Moss C, Rigg A, Van Hemelrijck M. COVID-19 and treatment with NSAIDs and corticosteroids: Should we be limiting their use in the clinical setting? Ecancermedicalscience. 2020;14.

63. Bersanelli M. Controversies about COVID19 and anticancer treatment with immune checkpoint inhibitors; 2020.

64. Clerkin KJ, Fried JA, Raikhelkar J, Sayer G, Griffin JM, Masoumi A, Schwartz A. Coronavirus disease 2019 (COVID-19) and cardiovascular disease. Circulation; 2020.

65. Hui David S, Azhar Esam I, Madani Tariq $A$, et al. The continuing 2019-nCoV epidemic threat of novel coronaviruses to global health- The latest 2019 novel coronavirus outbreak in Wuhan, China. International Journal of Infectious Diseases. 2020;91:264.

66. Deng Sheng-Qun, Peng Hong-Juan. Characteristics of and public health responses to the coronavirus disease 2019 outbreak in China. Journal of Clinical Medicine. 2020;9:2-575.

67. Grein J, Ohmagari N, Shin D, Diaz G, Asperges E, Castagna A, Nicastri E. Compassionate use of remdesivir for patients with severe Covid-19. New England Journal of Medicine; 2020.

68. Xu X, Han M, Li T, Sun W, Wang D, Fu B, Zhang $X$. Effective treatment of severe COVID-19 patients with tocilizumab. Proceedings of the National Academy of Sciences; 2020.

69. Zhang S, Li L, Shen A, Chen Y, Qi Z. Rational use of tocilizumab in the treatment of novel coronavirus pneumonia. Clinical Drug Investigation. 2020;18.

70. Wang C, Horby PW, Hayden FG, Gao GF. A novel coronavirus outbreak of global health concern. The Lancet. 2020; 395(10223):470-473.

71. Ashour Hossam M, Elkhatib Walid F, Rahman Md, et al. Insights into the recent 2019 novel Coronavirus (SARS-CoV-2) in light of past human coronavirus outbreaks. Pathogens. 2020;9:3-186.

72. Gu Tian, Chu Qiao, Yu Zhangsheng, et al. History of coronary heart disease increases the mortality rate of coronavirus disease 2019 (COVID-19) patients: A nested case-control study based on publicly reported confirmed cases in Mainland China. medRxiv; 2020.

73. Guo Yan-Rong, Cao Qing-Dong, Hong Zhong-Si, et al. The origin, transmission and clinical therapies on coronavirus disease 2019 (COVID-19) outbreak-an update on the status. Military Medical Research. 2020;7:11-10.

74. Meng L, Hua F, Bian Z. Coronavirus disease 2019 (COVID-19): Emerging and future challenges for dental and oral medicine. Journal of Dental Research; 2020.

75. De La Fip, Avis De Santé. Epimemie de coronavirus SARS-CoV-2: Informations et Lignes Directrices Provisoires.

76. Xiang Yu-Tao, Zhao Yan-Jie, Liu Zi-Han, et al. The COVID-19 outbreak and psychiatric hospitals in China: Managing challenges through mental health service reform. International Journal of Biological Science. 2020;16:10-1741.

77. Palmisano Lucia. Role of integrase inhibitors in the treatment of HIV disease. Expert Review of Anti-infective Therapy. 2007;5:167-7.

(c) 2020 Mbaye et al.; This is an Open Access article distributed under the terms of the Creative Commons Attribution License (http://creativecommons.org/licenses/by/4.0), which permits unrestricted use, distribution, and reproduction in any medium, provided the original work is properly cited.

Peer-review history:

The peer review history for this paper can be accessed here: http://www. sdiarticle4.com/review-history/56977 